\title{
High-Quality and High Mobility Concrete with Complex Nanostructured Additives
}

\author{
Abdullaev A.M. \\ Department of Physical and Mathematical Studies \\ Complex Research Institute named after Kh. I. Ibragimov, \\ RAS \\ Grozny, Russia \\ han-100@mail.ru
}

\author{
Abdullaev M.A-V. \\ Department of Materials Science \\ Complex Research Institute named after Kh. I. Ibragimov, \\ RAS Grozny, Russia \\ mgdaa@mail.ru
}

\author{
Paytayev Kh.A. \\ Graduate student \\ Complex Research Institute named after Kh. I. Ibragimov, RAS \\ Grozny, Russia \\ Paytaev88@mail.ru
}

\begin{abstract}
The paper presents the study of the influence of complex additives on strength properties of cement concrete. Complex nanostructured additives from various components containing nanosized particles received through the laboratory study are used in experiments. High strength of fine-grained concrete is obtained. The optimum concentration of additives of nanostructured mineral components together with superplasticizer thus ensuring high strength is established. The study shows that the developed nanostructured complex additives increase early and design strength, improve mobility and can be used in the production of self-compacting construction concrete.
\end{abstract}

Keywords-fine concrete, complex additive, nanostructured modifiers

\section{INTRODUCTION}

It is known [1-3] that one of the main and priority directions in construction materials science is the production of high-quality fine-grained concrete with improved mechanical and performance characteristics. The main advantages of fine-grained concrete include relatively easy design and decrease in labor input for their production due to lack of rigid heavy fillers and economy of fittings, as well as higher performance characteristics [4, 5]. Despite such advantages, there are some drawbacks related to relatively low strength properties, high cement consumption, stratification, bleeding and porosity increase, as well as lack of a rigid stone skeleton. Besides, extremely high specific surface of finegrained concrete components due to high water demand causes shrinking deformations. These drawbacks substantially narrow the scope of fine-grained concrete. There are various methods to improve the quality of fine-grained concrete where modifiers play a key role [6-10]. The concrete obtained using chemical additives is not always and does not fully satisfy high requirements of modern buildings and structures.

The purpose of this study is to increase the strength properties of fine-grained concrete using complex nanostructured additives, one of which is described in the given paper [12], thus improving the structure of a cement stone and quality of adhesion between a filler and a binding matrix.

\section{METHODS AND MATERIALS}

Cement of Chiri-Yurtovsky cement plant (the Chechen Republic) was used for the production of experimental samples of fine-grained concrete. The normal density of the cement paste was defined in accordance with GOST 310.3-76. The placeability of fine-grained concrete was determined by the cone slump in accordance with GOST 10181-2000 and GOST 7473-94. The compression strength was determined for cubic samples $(70.7 \times 70.7 \times 70.7 \mathrm{~mm})$ and the bending strength was determined for test beams $(4 \times 4 \times 16)$ using standard uniform sand in accordance with GOST 6139, the placeability corresponded to $\mathrm{P} 3$ with the cone slump of $13 \mathrm{~cm}$ and the deviation less than $2 \mathrm{~cm}$. The following were used in experiments as additives: Frem Giper S-TB superplasticizer, natural bentonite powder of the Chechen Republic (CR), water suspension of $\mathrm{CR}$ activated bentonite nanoparticles with the size of 128 nanometers and zol-gel nanoparticles of silicic acid. The efficiency of additives was defined in accordance with GOST 30459-2003. The surface of fine-grained concrete samples was studied via SEM using Quanta 3D 200i (USA).

\section{RESULTS}

To define the influence of various compositions of additives, the strength characteristics of fine-grained concrete were studied using uniform sand. The results are given in the Table 1. The joint use of surfactants shall make the system to improve this activity and hence, reduce the interfacial tension thus demonstrating a smoothing and condensing factor in cement composites [13, 14]. It was possible to reveal more accurate dependence of strength on the content of complex additives on the basis of nanostructured components. 
Table 1 shows strength indicators of test beams $(4 * 4 * 16$ based on portland cement of Chiri-Yurtovsky cement plant. $\mathrm{cm})$ of fine-grained concrete using standard uniform sand

TABLE I. STRENGTH Of Fine-Grained Concrete With AND Without AdDitives

\begin{tabular}{|c|c|c|c|c|c|c|c|c|c|}
\hline \multirow{2}{*}{$\begin{array}{l}\text { Cement, } \\
\text { g }\end{array}$} & \multirow{2}{*}{$\begin{array}{l}\text { Sand, } \\
\text { g }\end{array}$} & \multirow[t]{2}{*}{ Water, g } & \multirow{2}{*}{$\begin{array}{l}\text { Frem } \\
\text { Giper S- } \\
\text { TB, g }\end{array}$} & \multirow{2}{*}{$\begin{array}{l}\text { Natural } \\
\text { bentonit } \\
\text { e } \\
\text { powder, } \\
\text { g } \\
\end{array}$} & \multirow{2}{*}{$\begin{array}{l}\text { Nanosuspens } \\
\text { ion of } \\
\text { activated } \\
\text { bentonite, } \\
128 \mathrm{~nm}, \mathrm{~g}\end{array}$} & \multirow{2}{*}{$\begin{array}{l}\text { Zol-gel } \\
\text { nanoparticle } \\
\text { s of silicic } \\
\text { acid, g }\end{array}$} & \multicolumn{3}{|c|}{ Strength, MPa, sopprasion } \\
\hline & & & & & & & 1 day & 7 days & 28 days \\
\hline 500 & 1500 & 250 & & & & & $\frac{3.61}{1.15}$ & $\frac{22,81}{4,68}$ & $\frac{30,16}{5.38}$ \\
\hline 500 & 1651 & 193 & 2.5 & & & & $\frac{10.86}{3.22}$ & $\frac{35,58}{5.89}$ & $\frac{43,46}{5.94}$ \\
\hline 500 & 1666 & 187 & 2.5 & 1.5 & & & $\frac{10.79}{3.19}$ & $\frac{43,75}{5.97}$ & $\frac{47,66}{6.02}$ \\
\hline 500 & 1683 & 181 & 2.5 & & 3.0 & & $\frac{12.46}{3.73}$ & $\frac{40,96}{5.86}$ & $\frac{47.46}{5.92}$ \\
\hline 500 & 1693 & 177 & 2.5 & & & 1.5 & $\frac{11.88}{3.64}$ & $\frac{42,73}{5,84}$ & $\frac{53,86}{5.95}$ \\
\hline 500 & 1505 & 248 & & 1.5 & & & $\frac{3.69}{1.07}$ & $\frac{23.77}{4.59}$ & $\frac{30,56}{5.85}$ \\
\hline 500 & 1545 & 233 & & & 3.0 & & $\frac{6.82}{1.78}$ & $\frac{28.49}{4.59}$ & $\frac{33,99}{5.94}$ \\
\hline 500 & 1510 & 246 & & & & 1.5 & $\frac{4.73}{1.50}$ & $\frac{27,12}{4.60}$ & $\frac{35,26}{5.97}$ \\
\hline 500 & 1659 & 190 & 3.0 & & & & $\frac{11.87}{3.35}$ & $\frac{37.48}{6.01}$ & $\frac{47 / 41}{6.12}$ \\
\hline 500 & 1672 & 185 & 3.0 & 2.0 & & & $\frac{12.68}{3.28}$ & $\frac{42,53}{6.17}$ & $\frac{48,67}{6.18}$ \\
\hline 500 & 1706 & 172 & 3.0 & & 3.5 & & $\frac{13.56}{3.83}$ & $\frac{45,86}{5.98}$ & $\frac{51,46}{6.14}$ \\
\hline 500 & 1653 & 192 & 3.0 & & & 2.0 & $\frac{14.73}{3.77}$ & $\frac{47,84}{5.96}$ & $\frac{57,07}{6.15}$ \\
\hline 500 & 1500 & 251 & & 2.0 & & & $\frac{3.94}{1.15}$ & $\frac{24,52}{4.71}$ & $\frac{31,86}{5.94}$ \\
\hline 500 & 1547 & 232 & & & 3.5 & & $\frac{7.22}{1.85}$ & $\frac{30,59}{4.70}$ & $\frac{35,83}{6.02}$ \\
\hline 500 & 1500 & 250 & & & & 2.0 & $\frac{4.95}{1.57}$ & $\frac{27,82}{4,68}$ & $\frac{36,94}{6.08}$ \\
\hline 500 & 1666 & 187 & 3.5 & & & & $\frac{11.12}{3.29}$ & $\frac{36,52}{5.95}$ & $\frac{46,01}{5.98}$ \\
\hline 500 & 1677 & 183 & 3.5 & 2.5 & & & $\frac{11.81}{3.12}$ & $\frac{44,91}{5.88}$ & $\frac{50,12}{5.91}$ \\
\hline 500 & 1712 & 170 & 3.5 & & 4.0 & & $\frac{12.86}{3.61}$ & $\frac{41,96}{5.62}$ & $\frac{46,60}{5.89}$ \\
\hline 500 & 1659 & 190 & 3.5 & & & 2.5 & $\frac{12.96}{3.57}$ & $\frac{39,29}{5.81}$ & $\frac{54,10}{5.91}$ \\
\hline 500 & 1490 & 253 & & 2.5 & & & $\frac{3.97}{1.02}$ & $\frac{24,54}{4.56}$ & $\frac{30,99}{5.83}$ \\
\hline 500 & 1550 & 230 & & & 4.0 & & $\frac{6.88}{1.74}$ & $\frac{29,68}{4.57}$ & $\frac{33,85}{5.80}$ \\
\hline 500 & 1500 & 251 & & & & 2.5 & $\frac{4.44}{1.52}$ & $\frac{27,00}{4.54}$ & $\frac{35 / 44}{5.82}$ \\
\hline
\end{tabular}

When additives on the basis of bentonite clay and suspension of activated bentonite nanoparticles were introduced, the maximum compression strength of finegrained concrete with optimum concentration of additives exceeded the control values by 9 and $100 \%$, and the bending strength - by 0 and $61 \%$ in one day. The compression strength and the bending strength of samples with zol-gel nanoparticles of silicic acid exceeded the control values by $37 \%$ in one day of hardening. In 7 days of hardening the compression strength of these three additives is higher by $7.5,34$ and $22 \%$ respectively than for samples without any additives, and the bending strength is similar to the control samples. On the $28^{\text {th }}$ 
day of hardening the samples with bentonite powder, activated bentonite nanoparticles and zol-gel nanoparticles of silicic acid exceeded the control samples in compression strength by 5.6, 19 and $22 \%$ respectively, and in bending strength by 10 , 12 and 13\%. Separate use of Frem Giper S-TB increased the compression strength by 229,64 and $57 \%$ in 1,7 and 28 days of hardening, and the bending strength of the same samples were higher than the control samples by 191, 28 and $14 \%$ respectively.

Besides, samples with additives in a complex have the highest strength indicators with high mobility of fine-grained concrete mixes. The complex use of Frem Giper S-TB with bentonite powder increases the compression strength in 1, 7 and 28 days of hardening by 251,86 and $61 \%$, and the bending strength is higher the control samples by 185,32 and $15 \%$. As a result of complex introduction of suspension of activated bentonite nanoparticles together with Frem Giper S$\mathrm{TB}$, the compression strength in 1,7 and 28 days was higher the control samples by 276,101 and $71 \%$, and the bending strength of these samples in 1, 7 and 28 days exceeded the control samples by 233,28 and $14 \%$ respectively. Besides high bending and compression strength indicators, these samples have the lowest water-cement ratio. This effect of water reduction can also be explained by the decrease of mixing water interfacial tension if such additives are introduced in complex in comparison with other modifiers and their combinations $[11,12]$. The best result is achieved using the Frem Giper S-TB with zol-gel nanoparticles of silicic acid. In 1, 7 and 28 days of hardening the compression strength exceeded the control compositions by 308,110 and $89 \%$, and the bending strength exceeded the results of additive-free samples by 228,27 and $14 \%$. Thus, the use of bentonite powder, suspension of activated bentonite nanoparticles and zol-gel nanoparticles of silicic acid received in vitro separately and with Frem Giper S-TB superplasticizer in complex provides enough reasons for the broad use of these additives in production.

Considering the obtained features, fostering the strength improvement of fine-grained concrete based on the uniform sand with the use of complex additives, it was decided to study the surface of these samples further in this work. The scanning electron microscopy studied the contact zones between a filler and a cement stone, the porosity and density of structures on the basis of received micrographs.

Figures 1 and 4 show surface micrographs of samples from the table after destruction in 28 days of normal hardening.

The pictures of fine-grained concrete on the basis of standard uniform sand show the control sample with gaps almost in all places along the perimeter between grains of a filler and a cement stone. Besides, there are many pores and cracks on its surface. In addition, the areas of sample destruction are smooth and the cracks were mainly formed avoiding the filler, i.e. the sand grains after the concrete test remained almost unbroken. In comparison with control samples, the concrete surfaces with the use of complex additives have denser structure. According to Figures 3 and 4, the fracture of concrete samples mainly happened avoiding the filler grains when using the complex additives obtained by the combination of Frem Giper S-TB with the suspension of activated bentonite nanoparticles and zol-gel nanoparticles of silicic acid.

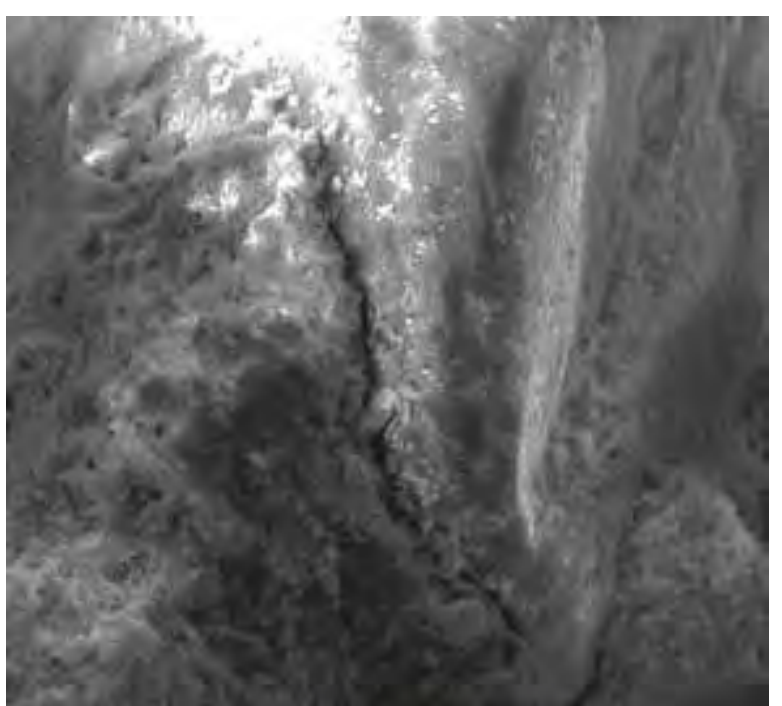

Fig. 1. Control sample

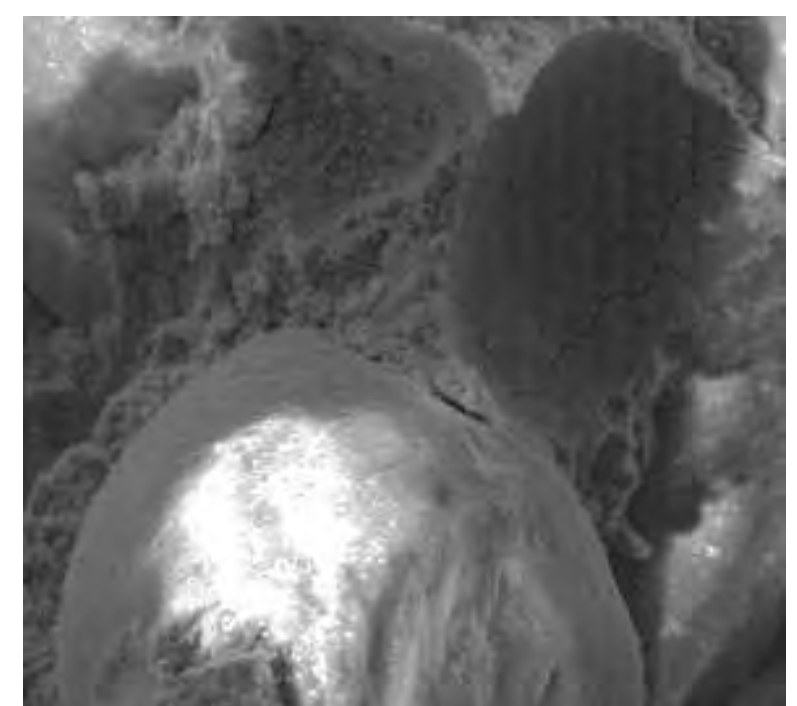

Fig. 2. Fine-grained concrete with complex additive from bentonite powder and Frem Giper S-TB after 28 days of normal hardening 


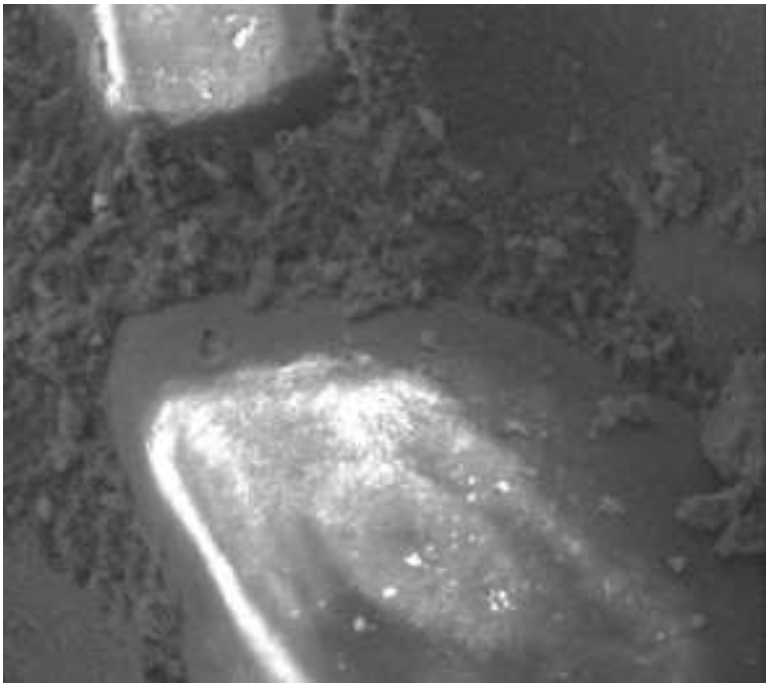

Fig. 3. Fine-grained concrete with complex additive from nanosuspension of activated bentonite and Frem Giper S-TB after 28 days of normal hardening

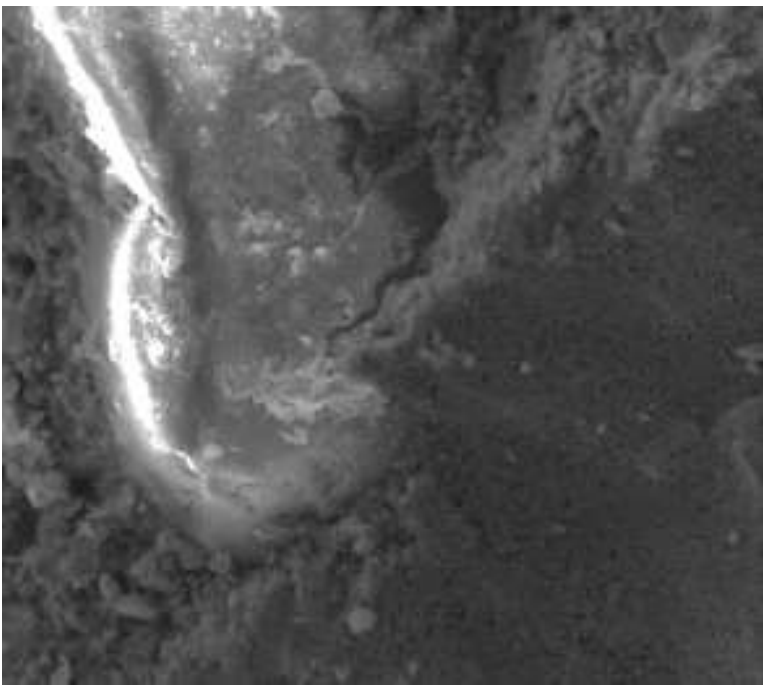

Fig. 4. Fine-grained concrete with complex additive from zol-gel nanoparticles of silicic acid and Frem Giper S-TB after 28 days of normal hardening
At the same time, higher density of contact between grains of the filler and the cement stone were also observed, which is explained by increased strength of concrete on the basis of complex additives (Table 1).

\section{CONCLUSIONS}

High-quality fine-grained concrete mixes with high mobility are received using the developed complex additives. The concrete mixes prepared using standard fillers showed the optimum dosage of the developed complex additives. The study of obtained mixes based on fine-grained concrete proved to be relevant for the formation of strong and dense cement stone. The given complex additives can be applied as modifiers contributing to the improvement of early and design strength at low water-cement ratio. According to GOST 24211-2003 "Additives for concrete and construction solutions", the studied complex additives belong to additives that improve strength, density and mobility of cement composites.

\section{References}

[1] Yu.M. Bazhenov, V.R. Falikman, B.I. Bulgakov, "Nanomaterials and nanotechnologies in modern concrete technology", MSUCE Bulletin. 2012, No. 12, pp. 125-133.

[2] Yu.M. Bazhenov, V.S. Demyanova, V.I. Kalashnikov, Modified highquality concrete. ASB, Moscow 2006, pp. 3-4.

[3] A.V. Usherov-Marshak, "Additives in concrete: progress and problems", Construction materials, 2006, No. 10, pp. 8-12.
[4] V.R. Falikman, "New effective high-functional concrete", Concrete technologies, 2011, No. 2, pp. 78-84.

[5] M.I. Yakupov, N.M. Morozov, I.V. Borovsky, V.G Khozin, "Modified fine-grained concrete for construction of monolithic runway surfacing of airfields", News of Kazan State Architectural and Construction University, 2013, No. 2, pp. 257-261.

[6] Yu.M. Butt, M.M. Sychev, V.V Timashev, Chemical technology of binding materials: Textbook for higher educational institutions, V.V. Timashev Ed. Mocow: High school. 1980, pp. 197-200.

[7] M.G. Davidson, Waterproofed concrete. Lineningrad:Lenizdat, 1965, pp. 28-39.

[8] N.F. Afanasyev, M.K. Tseluyko, Additives in concrete and solutions. Kiev: Budevilnik Publishing House, 1989, pp. 96-112.

[9] S-A.Yu. Murtazayev, D.K-S. Batayev, A.M. Abdullaev, M.S. Saydumov, A.Kh. Alaskhanova, "High-strength cement composites with complex additives based on nanostructured mineral components", Scientific review, No. 12, 2017, pp. 6-11.

[10] A.M. Abdullaev, S-A.Yu. Murtazayev, "Increase of cement specific surface with dispersion action of highly effective surfactants", Bulletin of BSTU named after V.G. Shukhov: Scientific and theoretical journal, 2016, No. 1, pp. 40-45.

[11] Kh. Dadashev, V.Kh. Mezhidov, R.S. Dzhambulatov, D.Z. Elimkhanov, "Features of isotherms of interfacial tension of bentonite water suspensions", RAS News. Physics, 2014, Vol. 78, No. 4, pp. 433-435.

[12] A.N. Smirnov, Definition of isotherms of interfacial tension of grain boundaries based on adsorptive measurements. Surface magazine. X-ray, synchrotron and neutron studies. May 2005, pp. 93-96.

[13] E.V. Mikheyeva, N.P. Pikula, S.N. Karbainova, Surface phenomena and dispersion systems. Colloidal chemistry. Collection of examples and tasks: manual for students. Tomsk: TPU publishing house, 2008, p. 116. 